\title{
Parkinson's disease: Can we move in the right direction?
}

\author{
Shane Hegarty
}

Department of Anatomy and Neuroscience, UCC

\section{'Imagine losing the control of your own movements'}

What do the worlds' greatest athlete and a wonderfully creative actor have in common?
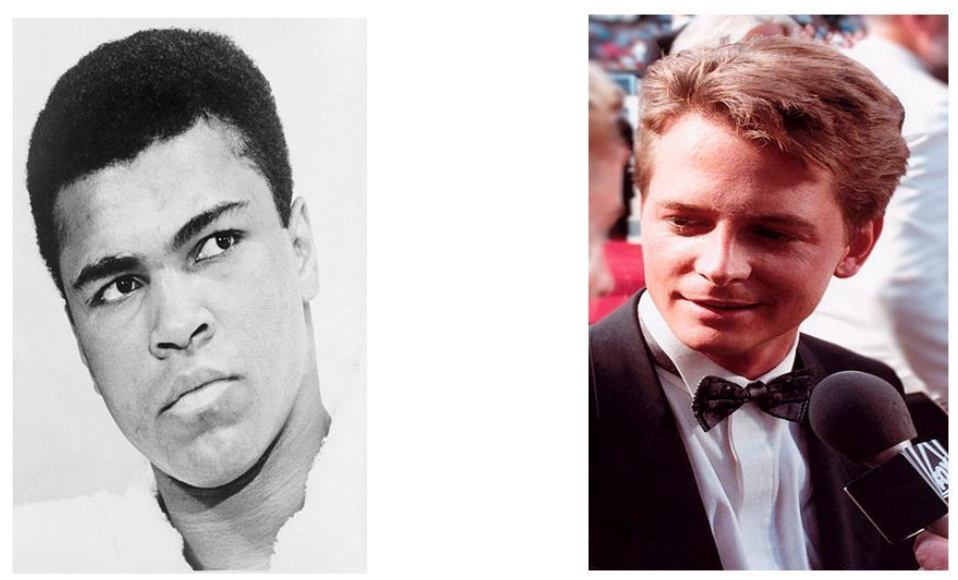

Figure 1: Parkinson's disease sufferers

They both suffer from Parkinson's disease. Imagine losing the ability to control your own movements! This is not just a reality for Muhammad Ali and Michael J. Fox, as $2 \%$ of the world's population over 65 suffer from this disease. Terrifyingly, the incidence of Parkinson's disease is set to double in the next 20 years as people are living longer.

\section{What happens in Parkinson's disease?}

In Parkinson's disease, a very important population of brain cells, known as dopaminergic neurons, die. Let's imagine these dopaminergic neurons as a tree, with the tree's roots in the midbrain, located between the spinal cord and brain, and the tree's branches in the brain. These branches produce dopamine, which allows us to control our movements. We can almost think of dopamine as the 'fruit' of this tree. These branches are killed in Parkinson's disease, and the dopamine (in red in the brain scans) is lost in the brain (see Fig. 2).

This loss of dopamine leads to the loss of our voluntary control of movement, which means that the sufferers cannot move in the way that they want. These Parkinson's patients can 


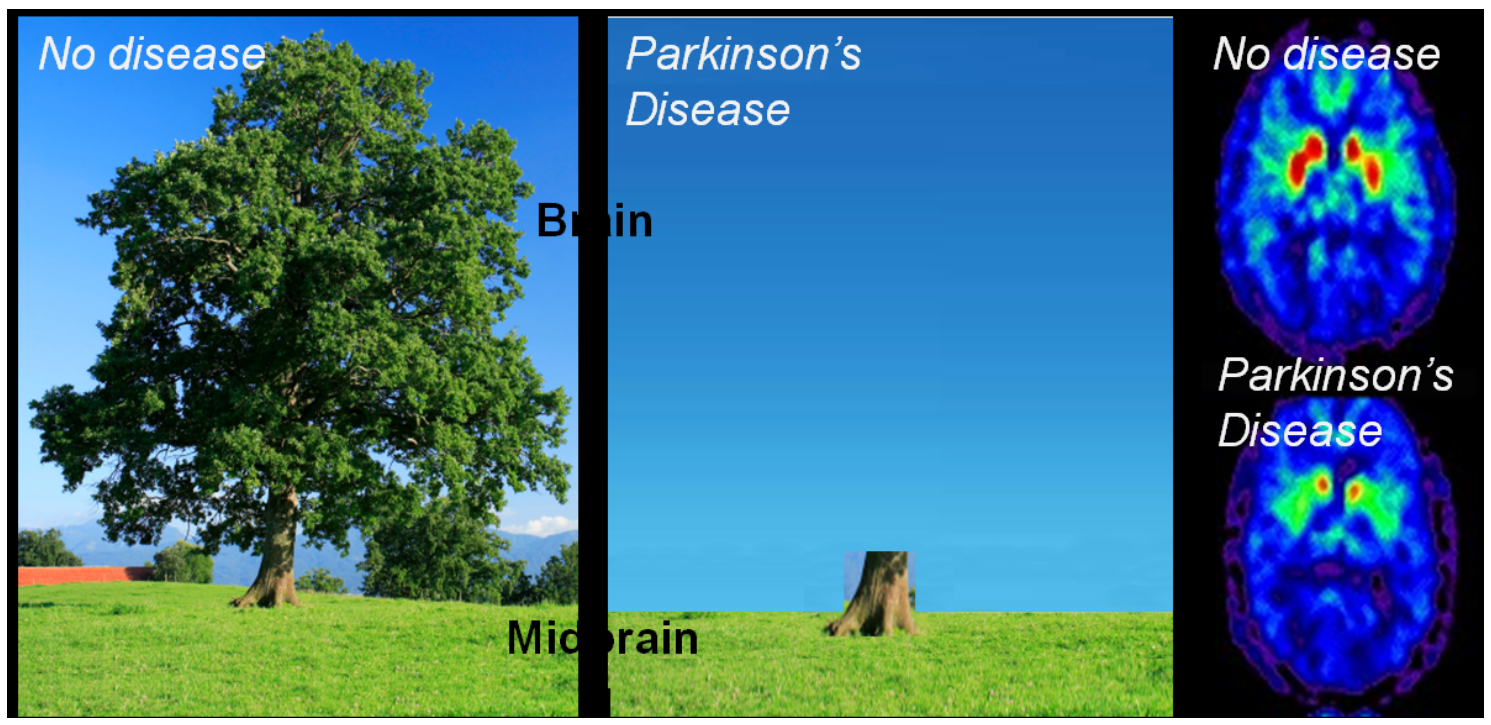

Figure 2: The dopamine tree

decide on the movements that they want to carry out, but they then cannot control how this movement occurs, or even if it occurs at all! It is hard to fathom the devastating effect that this disorder must have on a person's life.

\section{Why is dopamine so important?}

In a healthy brain, dopamine is released from the dopaminergic neurons and communicates with the brain to ensure that movements, decided upon by the brain, are carried out in a controlled manner. Without dopamine, this communication ceases, and the brain tells the body to move, or not move, in an uncontrolled manner. This communication breakdown between the midbrain and brain results in the movement symptoms of Parkinson's Disease, which are the 'shakes', stiffness, slow movement, and an unstable posture.

So how can we treat or cure Parkinson's disease patients? The main treatment for Parkinson's disease involves the replacement of the lost dopamine by giving drugs which either become dopamine (Levodopa) or act like dopamine. These drugs do provide relief from the symptoms of Parkinson's disease, however their effects wear off over time and they lead to disabling side effects. Furthermore, these current treatments do not stop, slow or cure the disease. Presently, there is no cure for Parkinson's disease.

\section{Can we move towards a Parkinson's disease cure?}

The fact that the loss of one, single, population of cells in the brain has such enormous consequences for the sufferer is scary. However, it provides the promising possibility that a cure for this disease may reside in finding a way to replace these specific cells. In order 


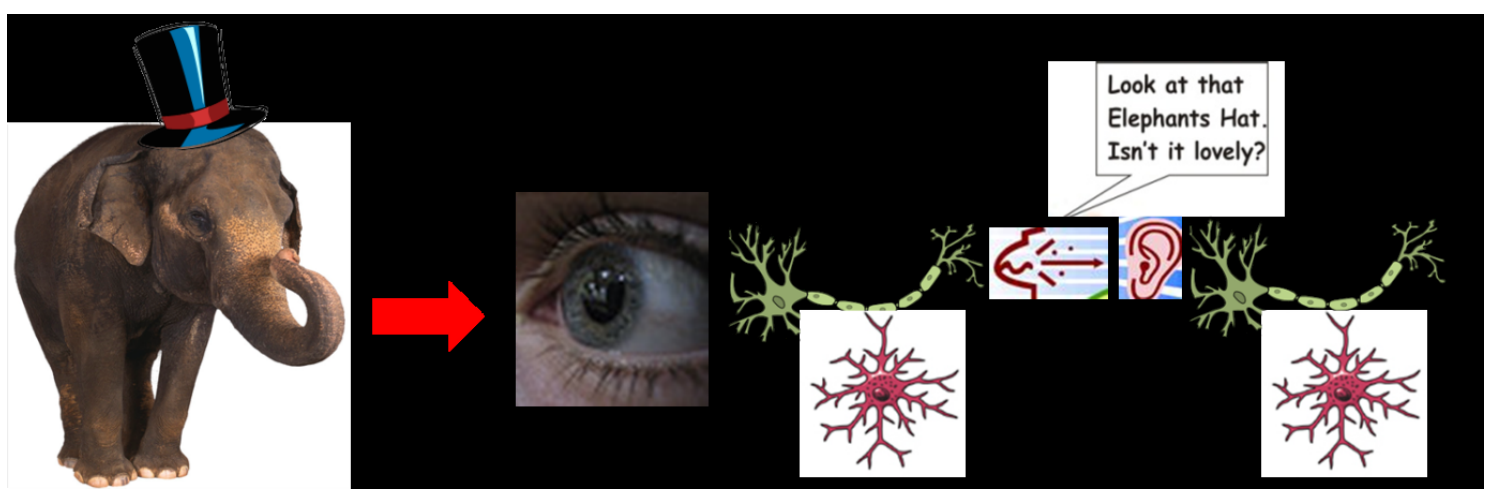

Figure 3: Neurons and glia

to replace the dopaminergic neurons, we would need to produce these brain cells. And in order to produce these dopaminergic neurons, we would first need to understand how they develop. That's where the focus of much of the research on Parkinson's disease now lies, and is the main aim of my study. So how do dopaminergic neurons develop? What we do know is that they are produced by brain stem cells at a precise time during a baby's development.

\section{Brain stem cells: Can a cure stem from them?}

Brain stem cells, or seedlings in the analogy of the tree, can develop into any brain cell type given the right signals. They can also multiply indefinitely, which means that they can potentially generate an unlimited number of brain cells. There are two main types of brain cells; neurons (green cells) which provide brain function, and 'glia' (red cells) which support the neurons (see Fig. 3). For example, when a person sees (eye) an elephant with a charming hat, neurons in the eye communicate with neurons in the brain (mouth and ear depict the communication between the neurons) to tell us what we're looking at. There are many different types of neurons, such as optic neurons for sight, auditory neurons for sound, and sensory neurons for sensation. The main goal of my research is to investigate how these brain stem cells turn into the dopaminergic neurons of the midbrain. I grow these brain stem cells in the laboratory under special conditions which allow them to survive and develop. I then add different signals to the brain stem cells to try and turn them into dopaminergic neurons.

\section{The big world of signals}

These signals are present in the nervous system as it develops, and each different region of the nervous system has a different combination of signals telling the brain stem cells what to turn in to, e.g., an optic neuron in the eye region, or an auditory neuron in the ear region. If we imagine the nervous system as Earth, then each country is a different region 


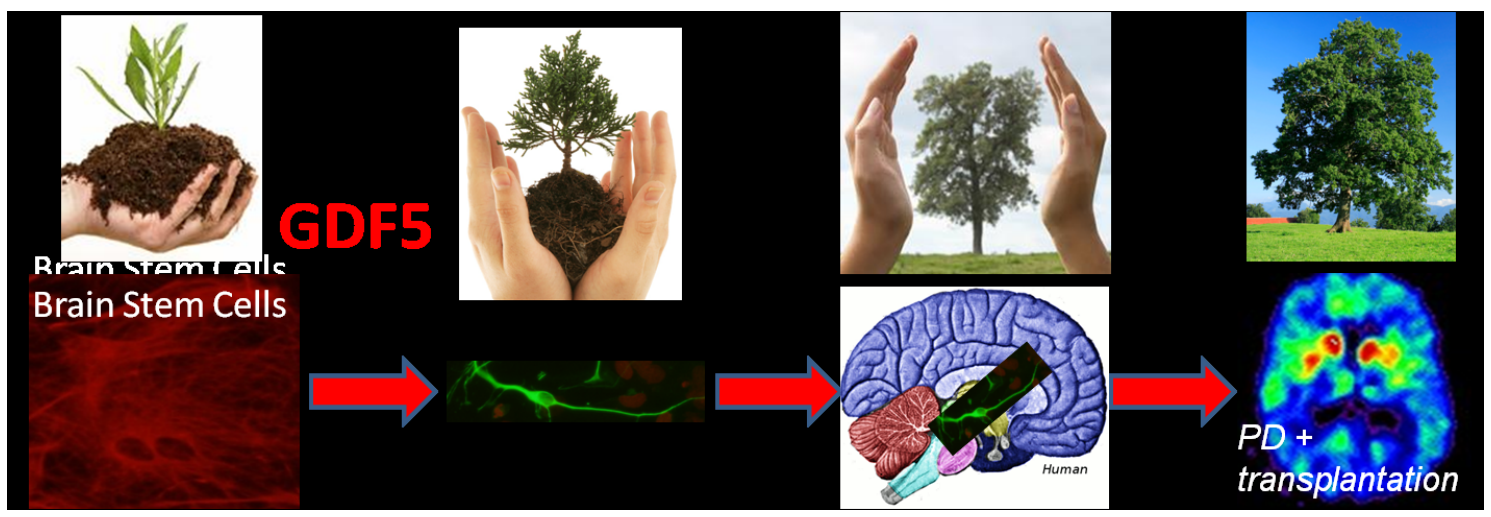

Figure 4: The production and replacement of dopaminergic neurons in Parkinson's disease

of the nervous system. If the brain stem cell is born and develops in France for example, then it will receive a specific combination of signals to become a French neuron. If we imagine these signals as the French language, and a strong affinity for berets and fresh croissants, then these 'signals' make a person French, excusing the stereotype.

Let's take this analogy a little further. Within these brain regions (or countries) there are different subtypes (populations) of brain cells (people) which behave in a different way to provide a separate function. Imagine, if you will, how a Cork person (such as me) behaves in a different way to someone from Dublin for example, despite the fact that we are both from Ireland. There are subtle differences in the signals that make subpopulations of brain cells from the same region of the nervous system unique. For example, the subtle (or not so subtle) difference between a Cork accent and a Dublin accent, if we imagine accents as another 'signal' that make us what we are. I am interested in what combinations of specific signals turn brain stem cells into dopaminergic neurons.

\section{GDF5: Good Day For 5cience}

From these experiments with brain stem cells and various biological signals, I have shown that one signal, known as GDF5, is capable of turning brain stem cells into dopaminergic neurons (see Fig. 3). This is a very encouraging result as it shows that dopaminergic neurons can be produced in the laboratory. However, there is much more research to be done until we know exactly how dopaminergic neurons develop, and what specific signals are involved in this development. That's where the future of my, and many other scientists, research lies for now. What is promising is that we are moving in the right direction. Whether this progress will allow Parkinson's patients to once again move correctly remains to be seen. 


\section{Where do we move next?}

What needs to be done next is to take these dopaminergic neurons that are produced in the laboratory, and transplant them into the midbrain of Parkinson's disease patients (see Fig. 4). Hopefully the 'branches' of these transplanted dopaminergic neurons will grow into the brain, take the place of the old, dead branches, and produce dopamine like before. If these transplanted cells achieve this, then they will likely restore the function that was lost when Parkinson's disease killed the old dopaminergic neurons. This is similar to how a transplanted organ achieves this in other clinical disorders. The fact that brain stem cells multiply indefinitely means that we have a renewable source of cells that can be used to produce dopaminergic neurons. This means that if these transplantations become a viable surgical therapy for Parkinson's disease, than there should be enough dopaminergic neurons produced for all sufferers of Parkinson's disease. What is most exciting about this ongoing research is that the transplantation of dopaminergic neurons could help Parkinson's patients all over the globe to once again control their movements.

Thanks to my supervisors Dr Aideen Sullivan and Dr Gerard O'Keeffe without whom none of this work would be possible, and all of my colleagues in the Department of Anatomy and Neuroscience. The author would like to acknowledge grant support from the Irish Research Council. Figures were composed by the author who has permission for all images used. 